Nigerian Journal of Physiological Sciences 19(1-2): 20-27@ Physiological Society of Nigeria 2004

\title{
HEARING ACUITY LOSS OF OPERATORS OF FOOD GRINDING MACHINES IN CALABAR, NIGERIA.
}

\author{
*S. A. BISONG, A. N. UMANA, V. ONOYOM-ITA, *E. E. OSIM. \\ Departments of *Physiology and ENT Surgery, College of Medical Sciences, University of Calabar, Nigeria.
}

\begin{abstract}
Summary: Noise has been generally found to cause hearing impairment. This was therefore a comparative study to determine whether chronic exposure to noise generated from food grinding machine can impair hearing acuity. Forty food grinding machine operators in Watt and Marian markets, Calabar, who were exposed to noise for at least 6 months formed the test subjects. Control subjects, however, were age- and sexmatched staff and students of the University of Calabar and University of Calabar Teaching Hospital, Calabar, who were exposed to low noise level. Results obtained showed that noise level in test sites (105.8 \pm $9.24 \mathrm{~dB}$ ) was significantly higher than that in the control sites $(55.5 \pm 1.78 \mathrm{~dB} ; \mathrm{P}<0.001)$. At every frequency tested, the machine operators had poorer hearing acuity than control subjects. The hearing threshold of the machine operators positively correlated with their duration of exposure at $2000 \mathrm{~Hz}$ and $4000 \mathrm{~Hz},(\mathrm{r}=0.357$, $\mathrm{P}<0.001 ; \mathrm{r}=0.444, \mathrm{P}<0.001$ respectively) and age at $2000 \mathrm{~Hz}, 4000 \mathrm{~Hz}$ and $8000 \mathrm{~Hz}(\mathrm{r}=0.266, \mathrm{P}<0.05 ; \mathrm{r}=$ $0.308, \mathrm{P}<0.01, \mathrm{r}=0.292, \mathrm{P}<0.01$ respectively). The prevalence of hearing loss among the machine operators was significantly higher (62.5\%), compared to control $(15.79 \%$; $\mathrm{P}<0.01)$. The incidence of symptoms such as tinnitus, insomnia and headache was also significantly higher in the test group (26.32\%, $21.05 \%$ and $34.2 \%)$ than in the control (5.26\%, 2.63\% and 5.26\% respectively; P < 0.01). Therefore, chronic exposure to food grinding machine noise at $105.8 \pm 9.24 \mathrm{~dB}$ can impair hearing acuity and associated risk factor appears to be prolonged exposure.
\end{abstract}

Key Words: Hearing Acuity, Noise, Grinding machine.

\begin{abstract}
Introduction
Many factors may adversely affect the hearing acuity of individuals. Among these are aging, exposure to noise, disease and ototoxic agents (Gates et al, 1990). Noise has long been recognized as a major cause of hearing impairment as shown by impaired hearing of coppersmiths usually referred to as "Coppersmith's deafness" in the eighteenth century and "blacksmith's deafness" in the nineteenth century (Manson \& Ludman, 1979). Sudden exposure to loud short-lived noise as in an explosion or gunfire can lead to permanent hearing loss, acoustic trauma. Chronic exposure to less intense but hazardous sounds can result in a gradual seemingly unnoticed deterioration of hearing sensitivity referred to as noise-induced
\end{abstract}

hearing loss (NIHL) (Fox et al, 1991) called occupational noise.

Studies of occupational noise exposure and its deleterious effect abound in literature (Klockhoff et al, 1986; Prosser et al, 1988; Kryter, 1991; Pekkarinen et al, 1993; Nondahl et al, 2000; Soleki, 2001; Sadhra et al, 2002). However, the intensity of noise and duration of exposure that may lead to hearing impairment is not certain. Furthermore, studies on noise have been done mostly on Caucasians. Studies on the effect of occupational noise among Africans are few. Osibogun et al (2000) found noise-induced hearing loss among textile workers in Lagos, Nigeria, who were exposed to environmental noise of more than $90 \mathrm{~dB}$. There were no reports on symptoms that may be associated to the noise. 
There are also no studies on chronic exposure to noise generated from food grinding machines, which is one of the occupational peculiarities of many Africans, particularly Nigerians. Such studies may assist governments in formulating legislation governing noise level at food grinding work places.

This study was therefore aimed at determining the hearing acuity of some Nigerian men and women chronically exposed to noise generated from food grinding machines and compared with sex- and age-matched controls. The incidence of symptoms that may be associated with the noise also determined and compared with control subjects.

\section{Materials and Methods}

Subjects for this study were selected from Calabar city in South Eastern Nigeria. For test subjects, food grinding machine operators in two major markets in Calabar were selected to undergo audiometric assessment. The control group was drawn from staff and students of the University of Calabar Teaching Hospital and the University of Calabar who were of the same age and who were exposed to low noise levels.

In order to exclude any other factors responsible for the reducing hearing acuity apart from noise from grinding machines, a thorough clinical history was taken and a questionnaire provided to identify previous ear disease, severe systemic illness, head injury or significant alternative noise exposure (McCombe et al, 1995). Subjects with a history of post traumatic hearing loss or having dizziness or tinnitus before involvement in grinding; those with the social habit of night clubbing or listening to loud music with head phones and those with history of childhood ear disease were excluded in the study. Also excluded were those who were found to have been treated with high doses of ototoxic drugs such as genticin, chloramphenicol and quinine (McCombe et al, 1992; McCombe et al, 1994). The exclusion criteria were also applied to the control subjects. The noise level at the sites of the grinding machines in the two markets and the control sites was measured using the sound level meter 72-860 (Tenma test equipment Springboro Ohio, USA). Informed consent was obtained from each participant at the beginning of the study (Nondahl et al, 2000) and the study carried out in accordance with the ethical standards of the ethical committee of the University of Calabar Teaching Hospital and with the Helsinki Declaration of 1975 revised in 1983.
The tests conducted were: otoscopy, puretone audiometry and a questionnaire to obtain information on the age, length of exposure, and other relevant information of the noise-exposed subjects and controls (Johanson et al, 2002). Before performing hearing assessment (audiometry) otoscopy was done (Nondahl et al, 2000) to further exclude subjects with abnormal findings. In some subjects, after otoscopic examination using the otoscope, wax or debris in the external auditory canal were removed using Aural syringe, Johnson Horne's probes and wax hook.

A total of 40 noise exposed subjects comprising 29 males and 11 females aged between 14 and 60 years were used as tests subjects, while 38 age and sex-matched subjects consisting of 29 males and 9 females who were not exposed to any hazardous noise acted as controls.

Hearing assessment of both test and control subjects was done using the pure-tone audiometer KC35 in the audiometric room of the University of Calabar Teaching Hospital, Calabar. Pure-tone audiograms were then obtained for both air and bone conduction. Air conduction audiograms were obtained for the conventional audiometric range $250 \mathrm{~Hz}$ to $8000 \mathrm{~Hz}$ (250, 500, 1000, 2000, 4000, and $8000 \mathrm{~Hz}$ ) and bone conduction audiograms obtained for the frequencies 250, 500, 1000, 2000 and $4000 \mathrm{~Hz}$ (McCombe et al, 1995).

Analysis of results was done for all the audiometric range of frequencies tested.

Prevalence of hearing loss (in percentage) at speech frequencies was defined as pure tone average for air conduction (at $500 \mathrm{~Hz}, 1000 \mathrm{~Hz}$ and $2000 \mathrm{~Hz}$ ) greater than or equal to $25 \mathrm{~dB}$, for the worse ear (Cruickshanks et al, 1998).

To investigate other symptoms resulting from exposure to noise generated from the grinding machines, the questionnaires provided also asked if the exposed subjects experienced tinnitus, insomnia or headache after work. The same questionnaires were also given to the control subjects. Blood pressure of the subjects was also measured.

\section{Statistical analysis:}

The values are expressed as means \pm standard error of the means and differences between means were assessed using the student's t-test. The relationship between hearing acuity and age, and hearing acuity and duration of exposure were determined using the multiple 
correlation coefficient. $\mathrm{X}^{2}$ was used to test for significance of prevalence of hearing loss and other symptoms.

\section{Results}

The noise-exposed subjects were 40 in number comprising 29 males and 11 females. They were aged between 14 years and 60 years; the mean age being $31.2 \pm 1.83$ years. The duration of exposure was between months to 18 years; the mean duration being $4.9 \pm 0.9$ years. They had no history of previous hearing impairment and non-treatment with high doses of ototoxic drugs.

The controls were 29 males and 9 females aged between 16 and 62 years, with mean age at $30.5 \pm 1.72$ years from the same area, Cross River State. The mean environmental noise level in the two market environments studied (105.8 \pm $9.3 \mathrm{~dB}$ ) was significantly higher than in control sites, which was $55.5 \pm 1.8 \mathrm{~dB}(\mathrm{P}<0.001)$.

\section{Air and bone conduction tests}

The hearing acuity of exposed subjects and their controls at different frequencies for air conduction showed that there was a significantly higher hearing threshold (hearing loss) among the noise-exposed subjects than their controls at every frequency tested $(\mathrm{P}<0.001)$. Fig 1 .

For bone conduction also, there was a significantly higher hearing threshold (hearing loss) among the exposed subjects than their control at every frequency tested $(\mathrm{P}<0.001)$. Fig 2

The prevalence (\%) of hearing loss among the food grinding machine operators was significantly higher than that of their control $(\mathrm{P}<$ 0.01). Out of the 40 food grinding machine operators, 25 (62.5\%) were found to have hearing loss, termed noise-induced hearing loss (NIHL). In the control group, 6 subjects (15.79\%) out of 38 had hearing impairment.

Relationship between hearing threshold at different frequencies with duration of exposure and age of exposed subjects for air conduction.

Fig 3 shows hearing threshold (in $\mathrm{dB}$ ) at different frequencies against duration of exposure and age of the exposed subjects (Fig 4). The duration of exposure correlated positively with the threshold of hearing at the frequency of $2000 \mathrm{~Hz}$ and $4000 \mathrm{~Hz}(\mathrm{r}=0.357$ and $\mathrm{r}=0.444$; $\mathrm{P}<0.001$ ) whereas, age correlated positively with the threshold of hearing at frequencies of 2000 , $4000 \mathrm{~Hz}$ and $8000 \mathrm{~Hz}(\mathrm{r}=0.266, \mathrm{P}<0.05 ; \mathrm{r}=$ $0.326, \quad \mathrm{P}<0.01$ and $\mathrm{r}=0.292, \mathrm{P} \quad<0.01$, respectively).

Other symptoms resulting from exposure to noise level above recommended exposure limit (REL)

A total of 38 noise-exposed subjects completed the questionnaire. Out of these, 10 subjects (26.32\%) had tinnitus; 8 subjects (21.05\%) experienced insomnia and 13 subjects (34.2\%) had headache at the close of work.

Of the 38 control subjects exposed to the barest minimum noise 2 subjects (5.26\%) complained having tinnitus, 1 subject $(2.63 \%)$ had insomnia while 2 subjects (5.26\%) had headaches. The frequency of symptoms (tinnitus, insomnia and headache) was significantly higher among the food grinding machine operators than in control subjects $(\mathrm{P}<0.01)$. Blood pressure in the two groups was not significantly different $(\mathrm{P}$ $<0.05)$. 
S. A. Bisong et al

Fig. 1. Air conduction test: Audiograms of food grinding machine operators (test) and their control subiects.

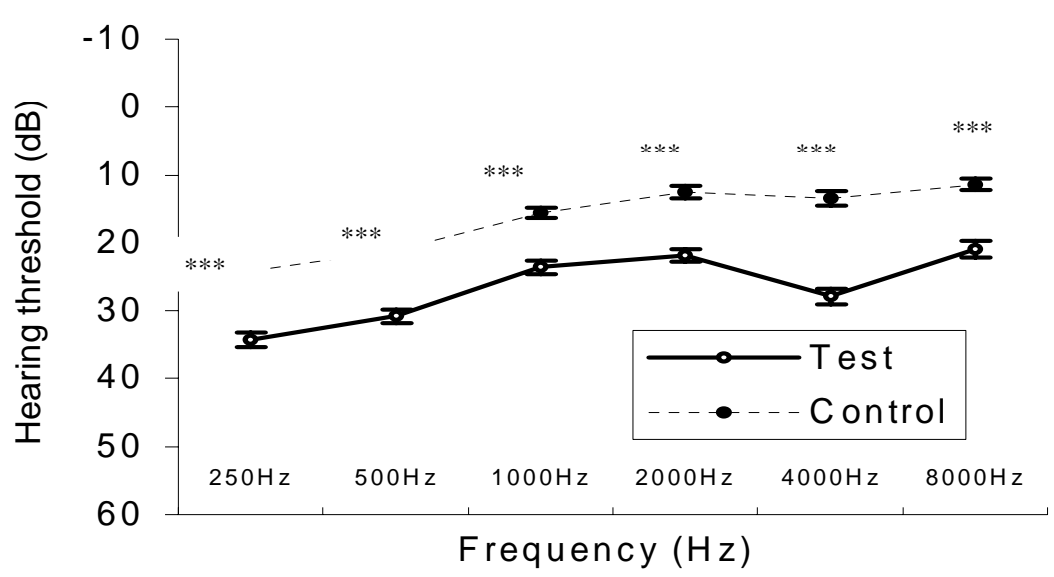

*** Significant at $P<0.001$ in comparison with control

Fig.2. Bone conduction test: Audiograms of food grinding machine operators (test) and their control subjects.

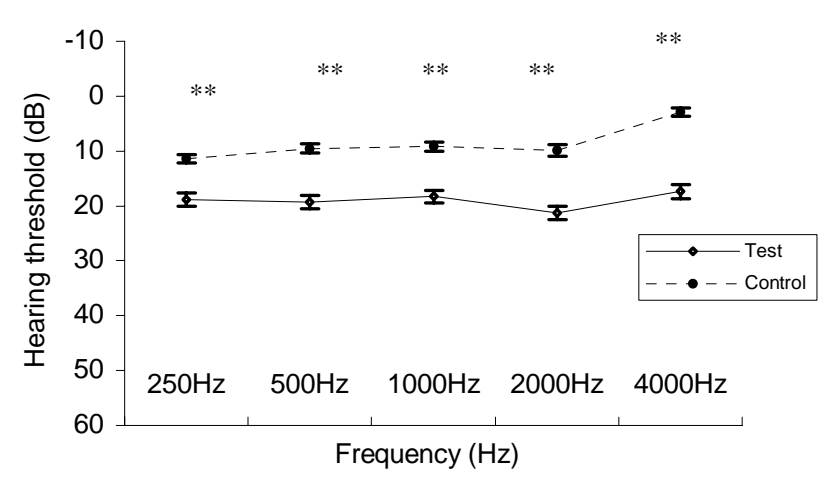

*** Significant at $P<0.001$ in comparison with control

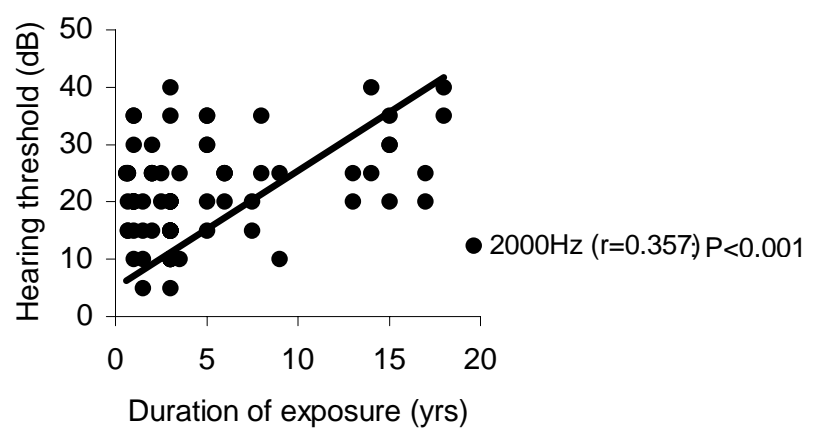




\section{S. A. Bisong et al}

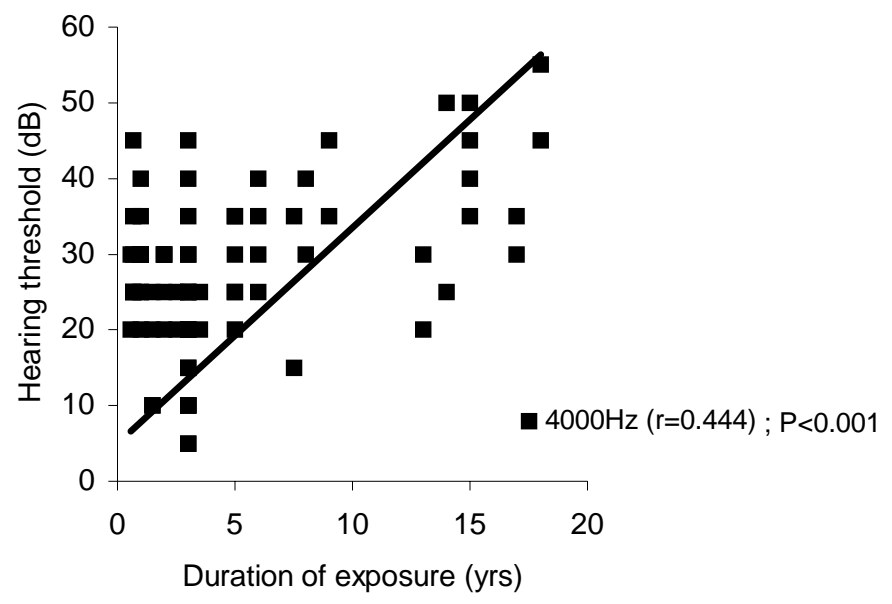

(b)

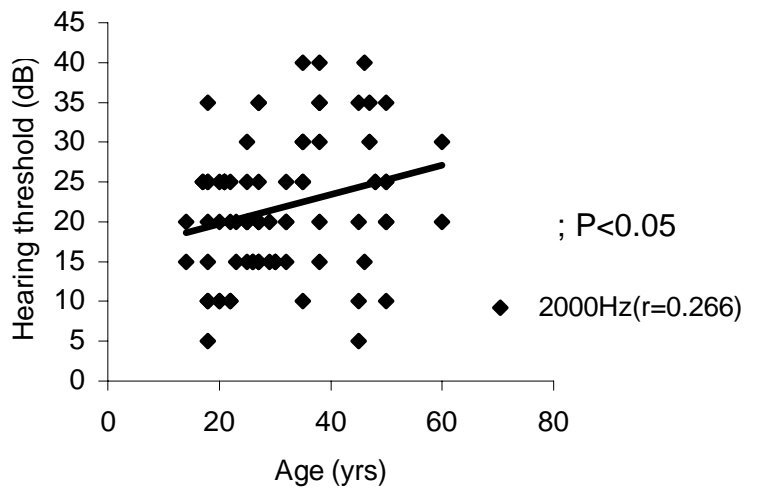

(a)

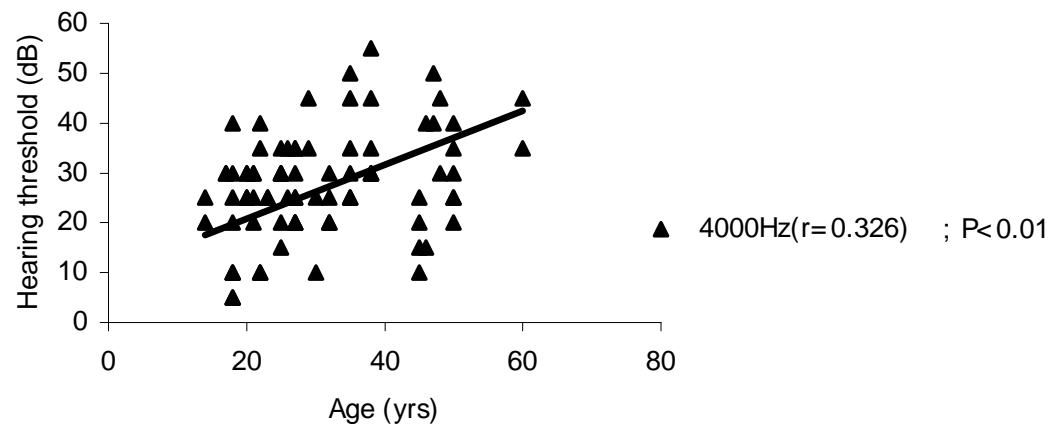

(b) 
(c) Fig. 4. Scatter of hearing threshold against age at $2000 \mathrm{~Hz}($ a), $4000 \mathrm{~Hz}$ (b) and $8000 \mathrm{~Hz}$ (c).
The noise level at grinding sites in Calabar markets was found to be $105.8 \pm 9.3 \mathrm{~dB}$, far in excess of the National Institute for Occupational Safety and Health (NIOSH) Cincinnati, Ohio USA, recommended exposure limit (REL) of 85dB (NIOSH, 1998) and also significantly higher than the noise in control areas (55.5 \pm $1.8 \mathrm{~dB}$ ). It is therefore likely that the hearing impairment observed may have been due to the exposure of noise generated by the food-grinding machine in the market places. This was shown by elevation of hearing threshold at all the frequencies tested and most markedly at the $4000 \mathrm{~Hz}$ among the grinding machine operators. Similar results of impaired hearing acuity have been shown due to noise $(90 \mathrm{~dB}-110 \mathrm{~dB})$ generated by motorcycles and wind (McCombe et al, 1993; McCombe et al, 1995). However, there are no reports on symptoms that may be associated with the noise studied.

operators. This should include education on the risk of noise to the ears and the enforcement of wearing ear protection devices in the food grinding machine industry.

In conclusion, chronic exposure to noise at intensity of $105.8 \pm 9.24 \mathrm{~dB}$ from food grinding machine can impair hearing acuity increase the incidence of tinnitus, insomnia and headache. Duration of exposure and age are associated risk factors.

\section{References}

Cruickshanks K.J, Klein R, Klein BE, Wiley TL, Nondahl DM, Tweed TS (1998). Cigarette smoking and hearing loss: the epidemiology of hearing loss study. JAMA; 3; 279(21): $1715-9$.

Erway LC, Shiau YW, Davis RR, Krieg EF (1996). Genetics of age-related hearing loss in mice III. Susceptibility of inbred and $F_{1}$ hybrid strains to noise-induced hearing loss. Hear Res; (3(1-2): 181-7.

Fox R et al (eds). (1991) Noise and Hearing loss. The Lancet; No. 8758; 338:21-22.

Gates GA, Cooper J C Jr., Kannel WB, Miller NJ. (1990) Hearing in the elderly: the Framingham Cohort, 1983-1985: Basic audiometric test results. Ear Hear; 11(pt1): 247-256.

Johansson MS, Arlinger SD (2002). Hearing threshold levels for an otologically unscreened, non-occupationally noiseexposed population in Sweden. Int J Audiol; 41(3): 180-94. 
Klockhoff I, Lyttkens L, Svedberg A. (1986). Hearing acuity in military service. A study on 38,294 conscripts. Scan Audiol.; 15(4): 217-22.

Kryter KD.(1991). Hearing loss from gun and railroad noise: relations with ISO standard. J. Acoust. Soc Am.; 90: 3180-3195.

Manson SR and Ludman H.(1979).Textbook of Otology ( $4^{\text {th }}$ ed.); Oxford, London. Pp. 465467.

McCombe AW, Binnington J, Bose R (1993). Wind noise and motorcyclists. Clin Otolaryngol; 18: 436.

McCombe AW, Binnington J, Davis A, Spencer H (1995). Hearing loss and motorcyclists. $J$ Laryngol Otol; 109: 599-604.

McCombe AW, Binnington J, Donovan D, McCombe TS (1992). Wind Noise and motor-cyclists. The Lancet; 340: 911-912.

McCombe AW, Binnington J, Nash D (1994). Two solutions to the problem of noise exposure for motorcyclists. Occup Med; 44: 239-242.

Molvaer OL, Lehmann EH (1985). Hearing acuity in professional drivers. Undersea Biomed Res; 12(3): 333-49.

Received: August 11, 2004

Accepted: October 6, 2004
Revised criteria 1998. U.S. Dept. of Health and Human Services Public Health Services. Center for Disease Control and Prevention. National Institute for Occupational Safety and Health. Cincinnati, Ohio. June 1998.

Nondahl DM, Cruickshank KJ, Wiley TL, Tweed TS, Klien BEK, Klein R (2000). Recreational fire arms use and Hearing loss. Arch Fam Med; 9: 352-357.

Osibogun A, Igweze IA, Adeniran LO (2000). Noise-induced hearing loss among textile workers in Lagos metropolis. Niger Postgrad Med J; 7(3): 104-11.

Pekkarinen J, Iki M, Starck J, Pyykko I (1993). Hearing loss risk from exposure to shooting impulses in workers exposed to occupational noise. $B r$ J Audiol; 27:175-182

Prosser S, Tartari, MC, Arslan E. (1988). Hearing loss in sports hunters exposed to occupational noise. Br J Audiol; 22:85-91

Sadhra S, Jackson CA, Ryder T, Brown MJ (2002). Noise exposure and hearing loss among student employees working in university entertainment venues. Ann Occup Hyg; 46(5): 455-63

Soloecki L (2001). Risk of noise-induced hearing loss in farm tractors operators. Med.Practice 52(4): 265-70.

NIOSH. (1998). Criteria for A Recommended Standard: Occupational Noise Exposure 